\title{
Association of Helicobacter pylori infection with gastric carcinoma
}

\author{
M.A. Majid ${ }^{1}$, T.I.M.A. Faruq ${ }^{2}$ and A.B.M. Bayezid Hossain ${ }^{3}$ \\ ${ }^{1}$ Department of Surgery, Bangabandhu Sheikh Mujib Medical University, Shahbag, Dhaka; ${ }^{2}$ Department of \\ Surgery, Dhaka Medical College, Dhaka; ${ }^{3}$ Department of Surgery, Sir Salimullah Medical College, Mitford, \\ Dhaka, Bangladesh.e-mail: dr_bayezid@yahoo.com
}

\begin{abstract}
This is a cross-sectional study on 140 gastric neoplasm subjects diagnosed by upper gastrointestinal endoscopy. The commonest site of cancer was the antrum of stomach $(52.86 \%)$, followed by the antrum and body (32.86\%) and only body region (12.14\%). Histology revealed adenocarcinoma in all patients. The associations of Helicobacter pylori with gastric cancer were studied by rapid urease test, serology and histology by Giemsa stain. The positivity of $H$. pylori determined by serology in 70 patients (50\%) was significantly higher than those determined by histology 22 patients (15.71\%). No significant association between $H$. pylori infection and gastric cancer was observed.
\end{abstract}

\section{Introduction}

Gastric cancer is one of the most common malignancies worldwide ${ }^{1}$. It tops the list of cancer related death in many countries of the world including countries in Asia. Gastric carcinogenesis is a multifactorial process ${ }^{2}$.

Gastric cancer is important historically and has been the subject of extensive research. Hippocrates first described a patient with black vomiting and a "karkinoma" of the stomach in $400 \mathrm{BC}^{3}$. Napoleon Bonaparte was found, at autopsy, to have a large gastric cancer that had perforated and, in fact, several members of the Bonaparte family were reported to have died from gastric cancer ${ }^{4}$. More recently, Marshall and Warren ${ }^{5}$ were awarded the 2005 Nobel Prize in Medicine and Physiology, in part for their discovery of Helicobacter pylori and its causative role in gastric cancer.

Recently it has been found that a casual relation may exist between $H$. pylori infection and gastric cancer. $H$. pylori cause chronic gastritis, gastric atrophy and intestinal metaplasia ultimately leading to gastric malignancy ${ }^{6}$. But the issue of carcinogenesis is yet unresolved because of discrepancy in epidemiological studies ${ }^{7}$. Most of the studies implicating $H$. pylori infection in the development of gastric cancer have been carried out in the developed countries in the west. The etiopathological background may be different among the people of this region ${ }^{8}$. The present study is likely to answer this question of co-relation between $H$. pylori and gastric carcinogenesis in Bangladesh.

\section{Materials and Methods}

This study was carried out from July 2006 to June 2007. One hundred forty endoscopically and histologically proven cases (male 105, femal 35) of gastric cancer were included. Patients with chronic disease, immunosuppressed, using non-steroid antiinflammatory, previous radiotheraphy/ chemotheraphy and $\mathrm{H}_{2}$ blockers were excluded. All patients were operated for gastric cancer (partial or total gastrectomy). After resection, the greater curvature of the stomach was opened and three to five mucosal biopsies samples were collected from nonnecrosed region of cancer and the adjacent macroscopically non-tumorous mucosa within $4 \mathrm{~cm}$ distance from the tumor margin. Two paired biopsies from non-cancerous part preferably antrum, body or body and fundus were taken.

The H. pylori infection status was assessed by the urease rapid test, observed during $30 \mathrm{~min}$ (Gastroteste kit). H. pylori IgG antibody in plasma was measured by an enzyme-linked immunosorbent assay (ELISA), using commercially available kit Cobas Core II (Roche). A cut off value of $>7.5 \mathrm{U}$ was taken to categorize positive samples, as recommended by the manufacturer. For histopathological evaluation of the $H$. pylori colonization, the specimens from tumor tissue and adjacent mucosa were loaded into $1 \%$ formalin and 
routinely screened with microscope (Giemsa staining).

One piece of each paired specimen was placed in the urea-agar media for rapid-urease test for detection of $H$. pylori. Other two mucosa biopsy specimens placed in alcohol and send to microbiology department for direct detection of $H$. pylori after Giemsa stain in addition to $\mathrm{H} \& \mathrm{E}$ staining.
Blood samples were taken from all the selected patients and the serum was assayed for anti $H$. pylori IgG by quantitative measurement with ELISA method.

Statistical analysis: Statistical analysis was done by Chi-square $\left(\chi^{2}\right)$. Proportion $(z)$ and correlation coefficient $(\boldsymbol{r})$ tests were done when and where applicable. A $p$ value of $<0.05$ was taken as statistically significant. It is done by using software SPSS 16.0 .

Table I: The result of different methods of detecting $H$. pylori in stomach cancer

\begin{tabular}{|c|c|c|c|c|c|c|}
\hline \multirow[b]{2}{*}{ Age } & \multicolumn{2}{|c|}{ Giemsa } & \multicolumn{2}{|c|}{ Rapid urease } & \multicolumn{2}{|c|}{ Serology (IgG) } \\
\hline & Negative & Positive & Negative & Positive & Negative & Positive \\
\hline $20-29$ & 8 & 2 & 7 & 3 & 5 & 5 \\
\hline $30-39$ & 16 & 2 & 16 & 2 & 8 & 10 \\
\hline $40-49$ & 29 & 5 & 26 & 8 & 21 & 13 \\
\hline $50-59$ & 23 & 2 & 19 & 6 & 12 & 13 \\
\hline $60-69$ & 25 & 6 & 23 & 8 & 15 & 16 \\
\hline $70-79$ & 15 & 3 & 13 & 5 & 8 & 10 \\
\hline $80+$ & 2 & 2 & 2 & 2 & 1 & 3 \\
\hline Total & 118 & 22 & 106 & 34 & 70 & 70 \\
\hline
\end{tabular}

\section{Results}

The mean ages of cancer patients were 51.48 years (range 20-85 years). Peak incidence (24.29\%) occurs in the age group 40 years to 49 years.

The $H$. pylori were detected in three methods (Giemsa, Rapid urease and serology). Using serology, there were 70 positive cases of $H$. pylori infection whereas only 34 and 22 cases were identified using rapid urease and Giemsa staining respectively (Table I).

The blood sample of all 140 patient of carcinoma stomach was analyzed for the detection of anti $H$. pylori IgG using the commercially available ELISA kits. The assay had a sensitivity of $>95.9 \%$ and a specificity of $98 \%$. Total 70 (50\%) patient of stomach cancer were $H$. pylori sero-positive, of which 15 female and 55 were male.

As per the site distribution (Table II) of gastric cancer, antral lesion comprised 52.86\% with antrum and body $32.86 \%$ and only body $12.14 \%$. $H$. pylori were positive in $54.05 \%$ (40/74) cases of lesion in antrum; 63.4\% (29/46) in antrum and body and $64.7 \%(11 / 17)$ in only body lesion. Only one $(0.71 \%)$ malignancy found in fundus area of stomach.

Table II: Distribution of gastric cancer

\begin{tabular}{lcc}
\hline Site & Number of patients & Percentage \\
\hline Antrum & 74 & 52.86 \\
Antrum and body & 46 & 32.86 \\
Body & 17 & 12.14 \\
Body and fundus & 2 & 1.43 \\
Fundus & 1 & 0.71 \\
\hline
\end{tabular}

Table I shows the age wise distribution of $H$. pylori presence by different methods of detection in carcinoma stomach. If we combine all methods then total number of 82 positive found. It indicates that around $58.57 \%$ of stomach cancers were infected with $H$. pylori.

\section{Discussion}

Once clinical manifestations appear, gastric cancer has an extremely poor prognosis since a 5-year survival rate using currently available treatments, surgery and radio-chemotherapy, is less than $20 \%$. Therefore, the challenge in gastric cancer, as in many other cancers, is to prevent its development by detection and treatment of pre-cancerous lesions and elimination of known risk factors. In order to achieve this goal, it is necessary to understand the patho-mechanisms of gastric carcinogenesis. Although stomach cancer is an ancient disease, probably affecting man for several millennia, its pathogenesis remains obscure. Epidemiological studies of migrant populations suggest that gastric cancer is associated with exposure to some environmental factor early in life ${ }^{9}$.

The association between $H$. pylori and gastric cancer was proven by numerous case control studies nested in large cohorts which could prospectively examine the $H$. pylori status of gastric cancer patients ${ }^{9-11}$. This association was considered sufficient by the Working Group of the International Agency for Research on 
Cancer/World Health Organization to recognize $H$. pylori as a Group I carcinogen for humans in $1994^{12}$.

Since then, data from several epidemiological, interventional and experimental studies have been gathered, confirming the causal link between $H$. pylori and gastric cancer. Ecological studies mostly confirm the geographical association between the prevalence of $H$. pylori and prevalence of gastric cancer, showing a declining incidence of gastric cancer in countries with falling rates of $H$. pylori infection. The results obtained with an animal model, the Mongolian gerbil, mimicking the gastric carcinogenesis steps after $H$. pylori infection, is another strong $\operatorname{argument}^{13}$.

In our study only $15.71 \%$ of gastric carcinoma patient were histologically positive for $H$ pylori. Though the prevalence of $H$. pylori infection in the apparently healthy young adults is reported to be $92 \%{ }^{14}$ in Bangladesh, which was much higher.

Lee et $\mathrm{al}^{15}$ in 1998 shows $H$. pylori infection rates were $78.9 \%$ in gastric cancer patients and $41.6 \%$ in normal control subjects ( $\mathrm{OR}=7.03$; $p<0.0005)$, which is not matching with our study.

A study in Korea ${ }^{16}$ reported that the infection rates showed only a slight difference between gastric cancer patients (60\%) and control subjects (51.9\%).

In this preliminary study, we found that among specimens of 140 stomach cancer patients $15.71 \%$ were infected with $H$. pylori by Giemsa stain in either the tumor or tissues adjacent to the tumor. Interestingly, however, only $8.57 \%(12 / 140)$ was Giemsa test-positive among tumor specimens, while $14.28 \%$ (20/140) was positive among tissues adjacent to the tumor. The tissues adjacent to the tumor may be more suitable for $H$. pylori detection than the tumor itself, presumably reflecting the preferred habitat of $H$. pylori.

In our study $H$. pylori positive carcinoma stomach found different in different methods like Giemsa= $15.71 \%$, rapid urease $=24.285 \%$, serology $=50 \%$. It indicates that carcinoma itself decrease the $H$ pylori infection rate. Serology (IgG) indicates old infection. So carcinoma itself may create a hostile environment for $H$. pylori growth.

These results suggested that $H$. pylori infection may not play a certain role in the early stage of carcinogenesis of gastric mucosa epithelia.

\section{Acknowledgments}

We acknowledge research and training monitoring cell of Bangladesh College of Physicians and Surgeons for providing fund for the study and Dr. Abdul Mazid Millon for collecting data from the patient.

\section{References}

1. Sepulveda AR, Graham DY. Role of Helicobacter pylori in gastric carcinogenesis. Gastroenterol Clin N Am. 2002; 31: 517-35.

2. Tang YL, Gan RL, Dong BH, Jiang RC, Tang RJ. Detection and location of Helicobacter pylori in human gastric carcinomas. World J Gastroenterol. 2005; 11: 1387-91.

3. Wolff J, Ayoub B, Jarcho S. The science of cancerous disease from earliest times to present. New Delhi, Amerind, 1989, pp 3-260.

4. Sokoloff B. Predisposition for cancer in the Bonaparte family. Am J Surg. 1938; 40: 673-78.

5. Marshall BJ, Warren JR. Unidentified curved bacilli in the stomach of patients with gastritis and peptic ulceration. Lancet 1984; 1: 1311-15.

6. Zhong LW, Xiong Z, Yao S, Jiang DQ, Dong XS. Effect of Helicobacter pylori infection on gastric epithelial proliferation in progression from normal mucosa to gastric carcinoma. World J Gastroenterol. 1998; 4: 246-48.

7. Sipponen P, Kosunen TU, Valle J, Riihelä M, Seppälä $\mathrm{K}$. Helicobacter pylori infection and chronic gastritis in gastric cancer. J Clin Pathol. 1992; 45: 319-23.

8. Khanna AK, Seth P, Nath G, Dixit VK, Kumar M. Correlation of Helicobacter pylori and gastric carcinoma. J Postgrad Med. 2002; 48: 27-28.

9. Nomura A, Stemmermann GN, Chyou PH, Kato I, Perez-Perez GI, Blaser MJ. Helicobacter pylori infection and gastric carcinoma among Japanese Americans in Hawaii. N Engl J Med. 1991; 325: 1132-36.

10. Parsonnet J, Vandersteen D, Goates J, Sibley RK, Pritikin J, Chang Y. Helicobacter pylori infection in intestinal- and diffuse-type gastric adenocarcinomas. J Natl Cancer Inst. 1991; 83: 640-43.

11. Forman D, Newell DG, Fullerton F, Yarnell JWG, Stacey AR, Wald N, Sitas F. Association between infection with Helicobacter pylori and risk of gastric cancer: Evidence from a prospective investigation. $\mathrm{Br}$ Med J. 1991; 302: 1302-05.

12. IARC Working Group. Schistosomes, liver flukes and Helicobacter pylori: Views and expert opinion of IARC working group on the evaluation of carcinogenic risks to humans. Lyon, France, IARC monographs, international agency for research on cancer. 1994; 61: 177-240.

13. Watanabe T, Tada M, Nagai H, Sasaki S, Nakao M. Helicobacter pylori infection induces gastric cancer in mongolian gerbils. Gastroenterology 1998; 115: 64248.

14. Ahmed MM, Rahman M, Rumi AK, Islam S, Haq F, Chowdhury MF, Jinnah F, Morshed MG, Hassan MS, Khan AK, Hasan M. Prevalence of Helicobacter 
pylori in asymptomatic population: A pilot serological study in Bangladesh. J Epidemiol. 1997; 7: 251-54.

15. Lee BM, Jang JJ, Kim JS, You YC, Chun SA, Kim HS, Han HM, Ahn MY, Byun SH. Association of Helicobacter pylori infection with gastric adenocarcinoma. Jpn J Cancer Res. 1998; 89: 597603.
16. Kim HY, Cho BD, Chang WK, Kim DJ, Kim YB, Park CK, Shin HS, Yoo JY. Helicobacter pylori infection and the risk of gastric cancer among the Korean population. J Gastroenterol Hepatol. 1997; 12: $100-03$. 